\title{
Article \\ Strains Comparisons of Unbound Base/Subbase Layer Using Three Elasto-Plastic Models under Repeated Loads
}

\author{
Ning $\mathrm{Li}^{1, *}$, Biao $\mathrm{Ma}^{2}$ and Hao Wang ${ }^{3, *}$ (I) \\ 1 School of Civil Engineering, Xi'an University of Architecture and Technology, Xi'an 710055, China \\ 2 Highway School, Chang'an University, Xi'an 710064, China; mb@gl.chd.edu.cn \\ 3 Department of Civil Engineering and Environmental Engineering, Rutgers, State University of New Jersey, \\ Piscataway, NJ 08854, USA \\ * Correspondence: lining_sn@xauat.edu.cn (N.L.); hwang.cee@rutgers.edu (H.W.); \\ Tel.: +86-137-725-24365 (N.L.)
}

Citation: Li, N.; Ma, B.; Wang, H. Strains Comparisons of Unbound Base/Subbase Layer Using Three Elasto-Plastic Models under Repeated Loads. Appl. Sci. 2021, 11, 9251. https://doi.org/10.3390/app11199251

Academic Editor: Jorge de Brito

Received: 30 August 2021

Accepted: 2 October 2021

Published: 5 October 2021

Publisher's Note: MDPI stays neutral with regard to jurisdictional claims in published maps and institutional affiliations.

Copyright: (c) 2021 by the authors. Licensee MDPI, Basel, Switzerland. This article is an open access article distributed under the terms and conditions of the Creative Commons Attribution (CC BY) license (https:// creativecommons.org/licenses/by/ $4.0 /)$.
Abstract: The constitutive model is the crucial part for the finite element analyses. To study the elasto-plastic properties of unbound granular materials (UGMs) under repeated vehicular loads, an elasto-plastic constitutive model called revised spatially mobilized plane (SMP) was proposed and validated. In this study, the revised SMP model was used for the plastic strain analyses of a typical three-layer pavement structure. To make comparisons, the Mohr-Coulomb and Druck-Prager models were employed for the numerical computation. The results show that plastic tensile and compressive strains in the horizontal and vertical directions appear on the top surface of UGM using the revised SMP model, but no plastic strains are produced by the Mohr-Coulomb and Druck-Prager models. The distribution of plastic strains in the revised SMP model had a good relationship with the actual loading areas under the vehicular loading, which related to the rutting. With the Mohr-Coulomb and Druck-Prage models, a great plastic strain was produced during the first several loading cycles and hardly increased in the following loading cycles, while the plastic strain in the revised SMP model presented an obvious increasing tendency with increased loading cycles. The predicted permanent deformations of the revised SMP, Mohr-Coulomb and Druck-Prage models were $0.557 \mathrm{~mm}, 0.78 \mathrm{~mm}$ and $0.155 \mathrm{~mm}$, respectively. Our work reveals that the Mohr-Coulomb model may over-predict and Druck-Prage model may under-predict the rutting of pavement in early loading stage and the results proved that the revised SMP model had advantages in the description of the plastic strain of UMG under repeated loads.

Keywords: unbound granular material; elasto-plastic model; plastic strain; revised SMP model; Mohr-Coulomb; Druck-Prage; repeated loads

\section{Introduction}

Unbound granular materials (UGMs), which are commonly used as the base or subbase courses in flexible pavements, have excellent adaptability for different conditions. However, UGMs have some disadvantages affecting their usage in pavement. It is inevitable that plastic deformation will occur during the whole service life of a road [1,2]. Some damages are caused by the plastic strain of UGM, such as rutting and cracks, resulting in a lower service level and shorter service life of the pavement. One of the main reasons is that UGMs are a typical elasto-plastic material, and plastic strain will appear under vehicular loads, especially the repeated loads [3-6]. To better understand the elasto-plastic properties of UGMs, the constitutive relationship is a critical concern for the stress-strain analyses of pavement structures $[3,5,6]$.

The elasto-plastic properties of UGMs have attracted abundant attention for the mechanical analyses of pavement structures [3-6]. In current studies, the stresses and strains are often analyzed separately $[3,4,6]$. For the plastic strains, prediction models were established as effective tools from experimental tests or mechanical analyses [2,7-11]. 
These models consider various factors which would affect the plastic strains. The accuracy and practicality vary greatly however, according to the different application conditions. Aiming at studying the stress-dependency of UGMs, non-linear and anisotropic models were frequently used to describe the mechanical properties of UGM in the laboratory and field $[6,12-15]$. This kind of model was mostly used for the computation without considering the characteristics of plasticity. These aspects are the main current research directions of UGMs. Although the non-linear and anisotropic models are accepted widely, plastic strains are hardly considered in these models, especially for the repeated vehicular loads $[6,14]$. On the other hand, the prediction models of plastic strain are difficult to use for structural analyses calculations, therefore, the most appropriate way is to establish a rational elasto-plastic constitutive model to balance the stress and strain.

Considering the stress-dependent and plasticity of UGMs, Zhang et al. proposed a nonlinear anisotropic elasto-plastic (NAEP) constitutive model based on the Generalized Drucker-Prager criterion $[6,15]$. The model was implemented using the weak form equationbased finite element model without a material subroutine and validated by loading tests performed in a laboratory tank. Compared with the nonlinear anisotropic elastic model, the NAEP model gave similar fatigue life results but predicted greater rutting in the pavement [6]. This model took full account of the characteristics of UGMs, avoiding the complicated hardening law. However, the cumulative plastic strain process seems unclear in this model. Based on shakedown theory and the Drucker-Prager criterion, Chazallon et al. established an elasto-plastic model of UGMs using a simplified model which employed the linear kinematic hardening assumption and a non-associated flow rule [3,4]. Taking the short-term and long-term performance into account, this model was constructed by classical elasto-plastic theory, which can be used for the monotonic and repeated loads. The model was verified using multi-stage tests with satisfactory results, and the effects of stress can be captured accurately. However, the fixed yield surface in this model has some differences with the actual situation under repeated loads.

The Mohr-Coulomb model is one of the most classical elasto-plastic constitutive models, which has been used widely and conveniently for friction materials with three plastic parameters [16-18]. The Drucker-Prager model also has close relationship with the Mohr-Coulomb model. The parameters of the two models can be interconverted under plane strain condition $[3,4,6,15,19]$. To some extent, the two models have the same characteristics but different formations. Matsuoka et al. proposed the spatially mobilized plane (SMP) criterion which was regarded as an extension (the square means) of the MohrCoulomb criterion in three dimensions [20,21]. Using the SMP and Mohr-Coulomb criteria, it was found that the limiting stress calculated by the SMP criterion was greater than that obtained from using the Mohr-Coulomb criterion, which verified the importance of intermediate principal stress [20]. The SMP criterion included the first, second, and third effective stress invariants, which could conveniently reflect the shear and hydrostatic pressure effects. With these considerations, the SMP criterion can be preferable for the plastic yield criterion of UGMs. Moreover, the yield surface of SMP was smooth and without sharp angles, which can avoid the problem of convergence [22].

Based on the achievements of the model proposed by Chazallon et al., the authors constructed an elasto-plastic model which was called the revised SMP model [5]. The revised SMP model was constructed using the SMP yield surface, a simplified hardening law and the non-associated flow rule [5]. With the plastic strain rate and resilient strain, a relationship was established to describe the variation of yield surface along with the increase of loading cycles. The hardening law was separated into two parts, in which the kinematic hardening law was used for the process of loading-reloading in the repeated loads and the isotropic hardening law for the loading-unloading in the single load. This simplified hardening model contributed to a better understanding and clear description of the development of plasticity. With a subroutine, the revised SMP model was validated by a laboratory repeated loads test using the precision unbound material analyzer (PUMA). However, the revised SMP model has not been used for the numerical simulation of pave- 
ment structure, and the characteristics of calculation results are still unknown. Considering the relationship among the SMP, Mohr-Coulomb and Druck-Prager criteria, these three models were used in this work for the computation of pavement analyses.

\section{Objective}

The objective of this study is to make comparisons among the revised SMP model, Mohr-Coulomb and Druck-Prage models. Then, the characteristics of the revised SMP model can be found out in the pavement structure calculation under repeated loads. First, the keys points of the revised SMP model are introduced briefly in several parts. After that, a finite element model of a three-layer pavement structure is constructed for the response analyses using the revised SMP, Mohr-Coulomb and Druck-Prager models. Then, the horizontal and vertical plastic strains are calculated and analyzed among the three models. Moreover, the strains of different layers are obtained and compared for the three models and the previous results.

\section{Elasto-Plastic Constitutive Model}

\subsection{Method to Construct the Revised SMP Model}

To construct the elasto-plastic constitutive model of an UGM under repeated loads, the UGM is regarded as a continuous medium and in a state of small deformation. It is assumed that the UGM produces only elastic and plastic strains without creep $[5,6,16,23]$. Moreover, the hardening modulus of the UGM remains unchanged during the process of repeated loads. To simplify the model, the anisotropic characteristics are not considered in this study. According to the plastic increment theory, three aspects are required for the construction of the elastic-plastic model, which are yield surface, hardening law and plastic flow rule [3-5]. The detailed processes were displayed in the literature [5]. In this study, the key points were briefly introduced to understand the construction of the revised SMP elasto-plastic constitutive model of UGM, and a flowchart for the construction was drawn, as seen in Figure 1.
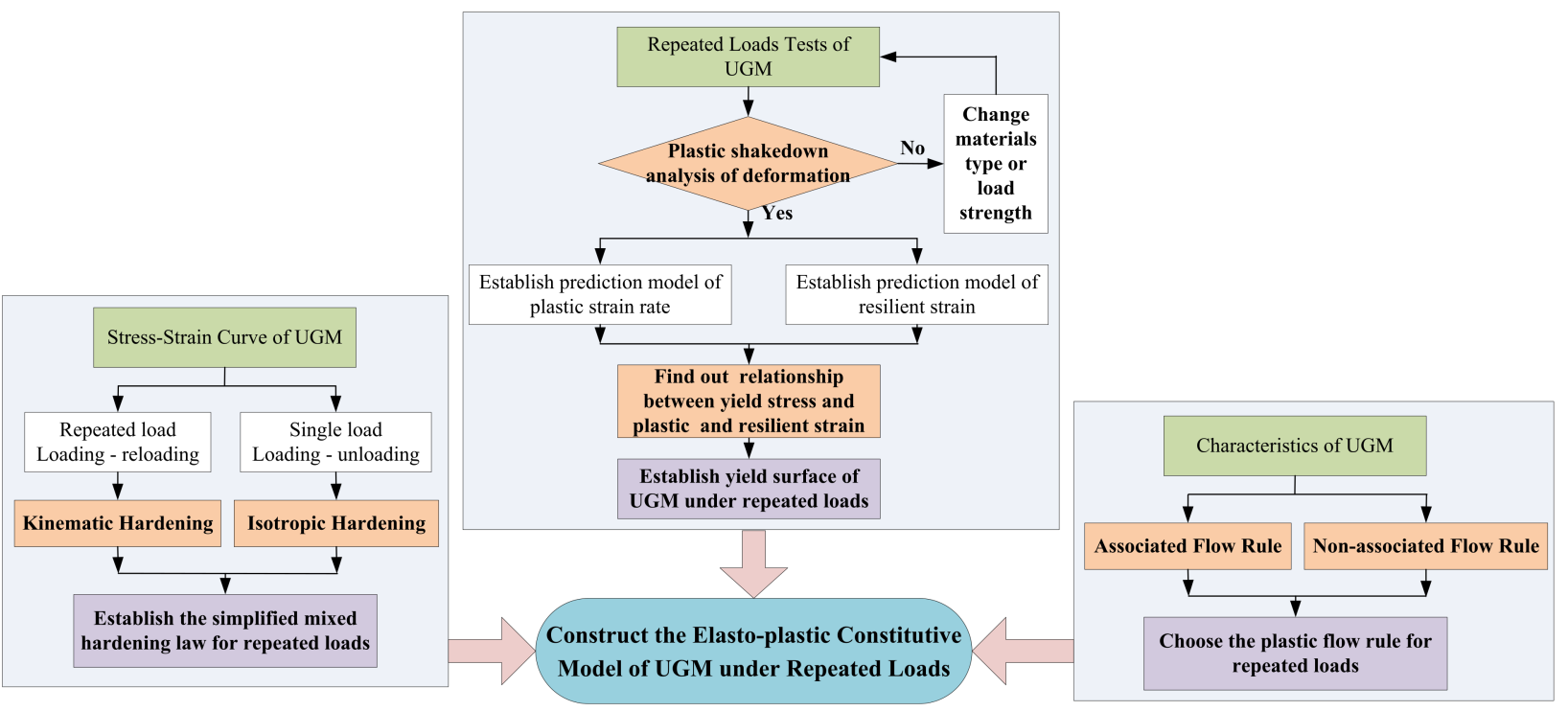

Figure 1. Flowchart of the construction of the revised SMP elasto-plastic constitutive model.

Among the three aspects, the yield surface is the primary concern. The SMP criterion is chosen as the yield criteria of the UGM. Shakedown theory and stress-strain analyses are involved in the establishment of the yield surface. There are five main steps to find out the features of the yield surface. Starting from the deformation behavior of UGM, shakedown theory was used to evaluate the plastic state under the current load [7,24,25]. In plastic shakedown range, the plastic strain rate and resilient strain was analyzed considering mul- 
tiple factors and the corresponding prediction models were constructed [11,26,27]. After analyses of the relationship between the yield stress and strains and modulus, the yield surface function was obtained through the prediction models of plastic strain rate and resilient strain $[5,28]$. Then, the variation features of yield surface were built under repeated loads, which were used for the construction of elasto-plastic model.

To characterize the relationship between stress and strain during the plastic stage, three hardening methods are used, the isotropic hardening, kinematic hardening and mixed hardening law, respectively. Actually, the mixed hardening law is the most suitable method to describe the actual hardening phenomenon, as the mixed hardening approach is usually too complicated for application and calculation. A simple hardening method was introduced in the revised SMP model. The kinematic and isotropic hardening was separately conducted without interaction effect. In this hardening law, kinematic hardening law was considered only during the reloading and isotropic hardening was used in the single loading period.

According to the relationship of yield surface and plastic potential surface, associated and non-associated flow rule were used to describe the direction of plastic stain. For the civil materials, the non-associated flow rule is commonly used for the plastic flow rule [3,4]. Then, the non-associated flow rule was used for the elasto-plastic constitutive model of an UGM.

\subsection{Key Points for the Revised SMP Model}

The implementation of the elasto-plastic constitutive model of UGM is introduced from the following four aspects:

(1) To determine the elasto-plastic yield surface of UGM under repeated loads, the steps are as follows:

Step 1: Carry out repeated loads test of UGM with more than three kinds of loading strength. Before the construction of the revised SMP model, a series of laboratory tests were conducted to obtain the experimental data. The gradation the tested UGM was designed by the interlocking skeleton method $[5,11,29,30]$. The optimum moisture content was $5.0 \%$, and the maximum dry density was $2.263 \mathrm{~g} / \mathrm{cm}^{3}$. The coefficient of curvature $(C c)$ and coefficient of uniformity $(\mathrm{Cu})$ was 26.95 and 2.72 , respectively.

The loading strength was determined depending on the axial stress range of UGM layer, the confining pressure was 10 50 kPa. For the long-term repeated load tests, four axial stresses $(80,160,240$ and $320 \mathrm{kPa})$ and four loading frequencies $(1,5,8$ and $10 \mathrm{~Hz})$ were used and the loading cycles were up to 20,000 repetitions $[11,29,30]$. In addition, three compaction degrees $(96 \%, 98 \%$ and $100 \%)$ and five moisture contents $(0,3 \%, 4 \%$, $5 \%$ and $6 \%$ ) were taken into account. Then the plastic strain rate and resilient strain was obtained, and which were calculated as follows:

$$
\begin{gathered}
\dot{\varepsilon}_{p(N)}=\varepsilon_{p(N)}-\varepsilon_{p(N-1)} \\
\varepsilon_{r(N)}=\varepsilon_{P K-P K(N)}-\dot{\varepsilon}_{p(N)}
\end{gathered}
$$

where, $\dot{\varepsilon}_{p(N)}$ is the plastic strain rate which means the plastic strain generated in the loading cycle of number of $N ; \varepsilon_{p(N)}$ is the cumulative plastic strain during the $N$ times of loading cycle; $\varepsilon_{p(N-1)}$ is the cumulative plastic strain during the $N-1$ times of loading cycle; $\varepsilon_{r(N)}$ is the resilient strain in the loading cycle of number $N ; \varepsilon_{P K-P K(N)}$ is the amplitude of the maximum strain and the minimum strain in the loading cycle of number $N ; N$ is the loading repetitions; $p$ represents 'plastic' and $r$ represents 'resilient'.

Step 2: Evaluate the shakedown state of UGM using shakedown theory. The requirement of plastic shakedown of UGM is that the cumulative plastic strain needs to meet the following condition:

$$
\left(\varepsilon_{p}^{5000}-\varepsilon_{p}^{3000}\right)<0.045 \times 10^{-3}
$$


where, $\varepsilon_{p}^{3000}$ is the cumulative plastic strain during the first 3000 times of loading; $\varepsilon_{p}^{5000}$ is the cumulative plastic strain during the first 5000 times of loading. If this condition is satisfied, UGM is regarded as being in a stable state under the current loading strength. If not, the material category or loading strength of UGM should be selected again, and the loading strength should preferentially be changed first.

Step 3: Establish the prediction models of plastic strain rate and resilient strain under plastic shakedown state, which consist of the loading strength, loading cycle, loading frequency, degree of compaction and moisture content. The models are as follows:

$$
\begin{gathered}
\dot{\varepsilon}_{p}=K_{f}^{p} \cdot K_{d}^{p} \cdot K_{m}^{p} \cdot a N^{b} \\
\varepsilon_{r}=K_{f}^{r} \cdot K_{d}^{r} \cdot K_{m}^{r} \cdot\left(A+B * C^{N}\right)
\end{gathered}
$$

where, $a, b, A, B, C$ are the parameters of the models, which can be expressed as the function of axial deviator stress $\sigma_{d}, a=f\left(\sigma_{d}\right)$, etc.; $K_{f}, K_{d}$ and $K_{m}$ are the correction coefficients of loading frequency, degree of compaction, and moisture content, respectively.

Step 4: Analyze the relationship between yield stress and plastic strain during the typical loading-unloading cycle in stepwise and repeated loads tests under the shakedown load, obtaining Equation (6).

$$
\sigma_{y}=\sigma_{\max }-\frac{A \boldsymbol{D}}{|\boldsymbol{D}|-A} \varepsilon_{p}
$$

where, $|\boldsymbol{D}|$ is the determinant of the elastic stiffness matrix $\boldsymbol{D} ; A$ is the hardening modulus in plastic stage; $\sigma_{y}$ is the yield stress; $\sigma_{\max }$ is the maximum axial stress; $\varepsilon_{p}$ is the plastic strain in a single loading cycle, which is regarded as a plastic strain rate $\left(\dot{\varepsilon}_{p(N)}\right)$ under repeated loads. To some extent, this equation establishes the relationship between the yield stress and plastic strain and resilient strain.

Step 5: Establish the plastic yield criterion of UGM under repeated loads based on the Spatial Mobile Plan (SMP) and Equation (6), as follows:

$$
f=\frac{I_{1} I_{2}}{I_{3}}=a * \exp \left(b * \frac{\sigma_{d} \cdot \exp \left(-\dot{\varepsilon}_{p(N)}\right)}{p_{a} \cdot \varepsilon_{r(N)}}\right)
$$

where, $I_{1}, I_{2}$ and $I_{3}$ are the first, second and third principal stress invariants, respectively; $\sigma_{1}$, $\sigma_{2}$ and $\sigma_{3}$ are the first, second and third principal stress, respectively; $p_{a}$ is the atmospheric pressure; $a$ and $b$ are the parameters of the model.

(2) To establish the plastic hardening law of UGM under repeated loads, two steps are used as follows:

Step 1: Using isotropic hardening method in the loading-unloading period under single load, plastic strain hardening model $H=\epsilon_{i j}^{p}$ is adopted by the recorded curve of stress-strain.

Step 2: Using a kinematic hardening method in the loading-reloading period under repeated loads, the approach that the plastic yield point moves forward with the stable hardening modulus parallel to the initial one is applied to guide the hardening under repeated loads.

(3) Choose the plastic flow rule of UGM under repeated loads, non-associated flow rule is used to obtain the direction of plastic strain. The potential surface of plastic flow is similar to the yield surface, which has a plastic potential parameter different from the yield hardening parameter.

$$
g=I_{1} I_{2}-k_{1} I_{3}=0
$$

where, $g$ is the potential surface of plastic flow; $k_{1}$ is the plastic potential parameter. The yield surface has the corresponding plastic potential surface, but they do not coincide. 


\subsection{Construct of Elasto-Plastic Constitutive Model of UGM}

Based on the plastic increment theory of classical elasto-plastic theory, the elasto-plastic constitutive model of UGM was constructed by the SMP yield function, non-associated flow rule and plastic strain hardening law. Then, the elasto-plastic stiffness matrix shown in Equation (9) is obtained:

$$
D_{i j k l}^{e p}=\left[\begin{array}{cccccc}
K+\frac{4}{3} G-m_{11}^{p} & K-\frac{2}{3} G-m_{12}^{p} & K-\frac{2}{3} G-m_{13}^{p} & 0 & 0 & 0 \\
K-\frac{2}{3} G-m_{21}^{p} & K+\frac{4}{3} G-m_{22}^{p} & K-\frac{2}{3} G-m_{23}^{P} & 0 & 0 & 0 \\
K-\frac{2}{3} G-m_{31}^{p} & K-\frac{2}{3} G-m_{32}^{p} & K+\frac{4}{3} G-m_{33}^{P} & 0 & 0 & 0 \\
0 & 0 & 0 & 2 G & 0 & 0 \\
0 & 0 & 0 & 0 & 2 G & 0 \\
0 & 0 & 0 & 0 & 0 & 2 G
\end{array}\right]
$$

where, $K$ is the bulk modulus, $G$ is the shear modulus of elasticity; $m_{i j}$ is the plastic section. This elasto-plastic matrix includes 15 parameters which are acquired from loaddecreasing tests, isobaric tests, and repeated load tests. A user-defined material (UMAT) subroutine was developed for the revised SMP model implemented in the numerical simulation [12,31,32]. The flowchart of the UMAT subroutine is shown in Figure 2.

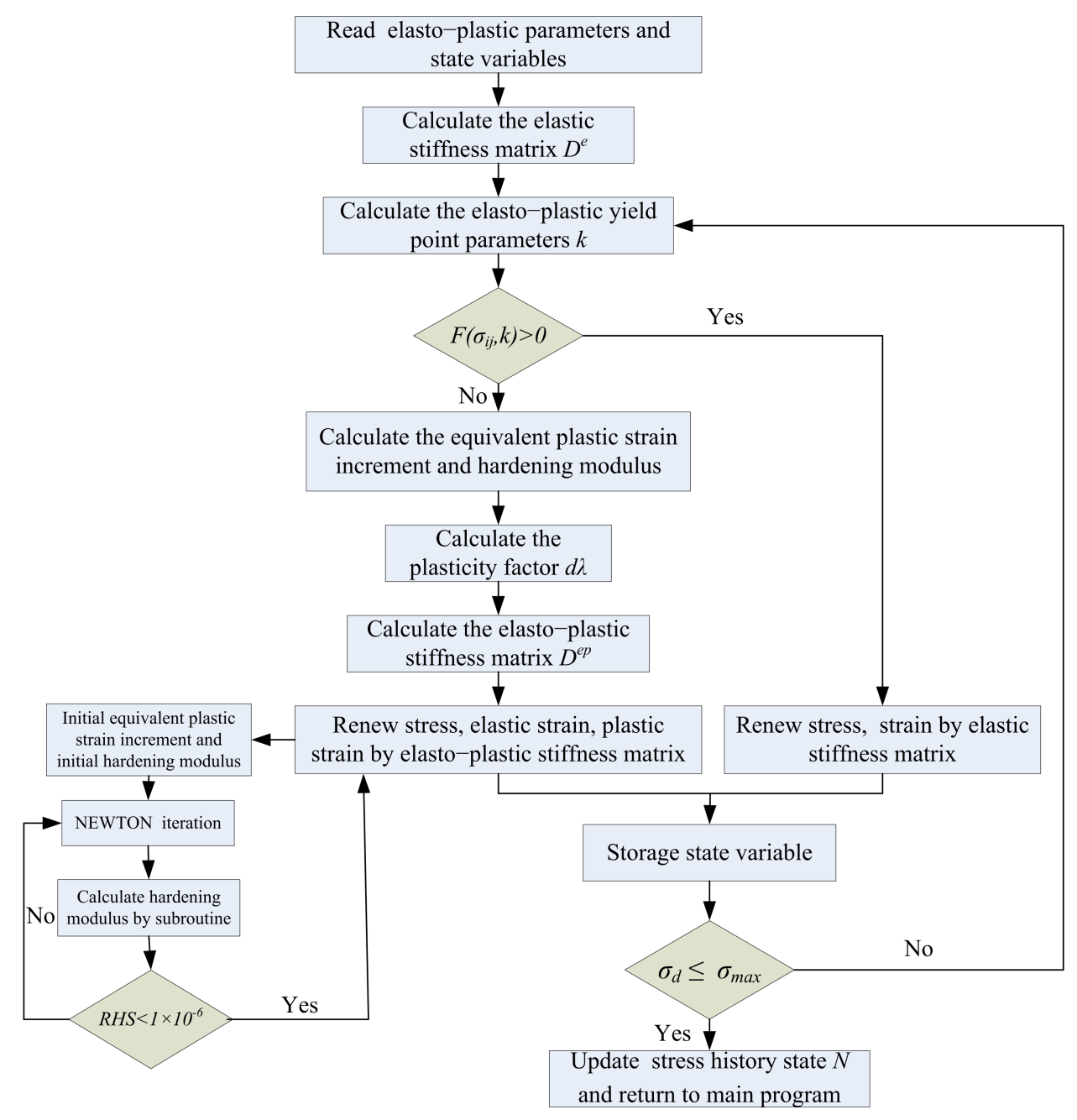

Figure 2. Flowchart of the UMAT subroutine. 


\subsection{Finite Element Model of Pavement Structure}

Using the general-purpose FE software ABAQUS, a 2-dimensional model was used to simulate the pavement structure, which was simplified into a three-layer system with $15 \mathrm{~cm}$ asphalt surface layer HMA $+25 \mathrm{~cm}$ unbound gravel layer UGM $+140 \mathrm{~cm}$ soil subgrade. The cross-section of the pavement structure was $6 \mathrm{~m}$ width and $1.8 \mathrm{~m}$ depth. Due to the symmetry of pavement structure and vehicular loading condition, the 1/2 2-Dimensional plane strain model was adopted, seen in Figure 3. The right and bottom boundary was designed as the encastre boundary condition (ENCASTRE), and XSYMM boundary condition $\left.\left(U_{1}=0\right)\right)$ was adopted for the symmetry axis in the left side. There were two contact surfaces in the FE model for the three layers. The types of the two contact surfaces were both the completely continuous in the FE model.

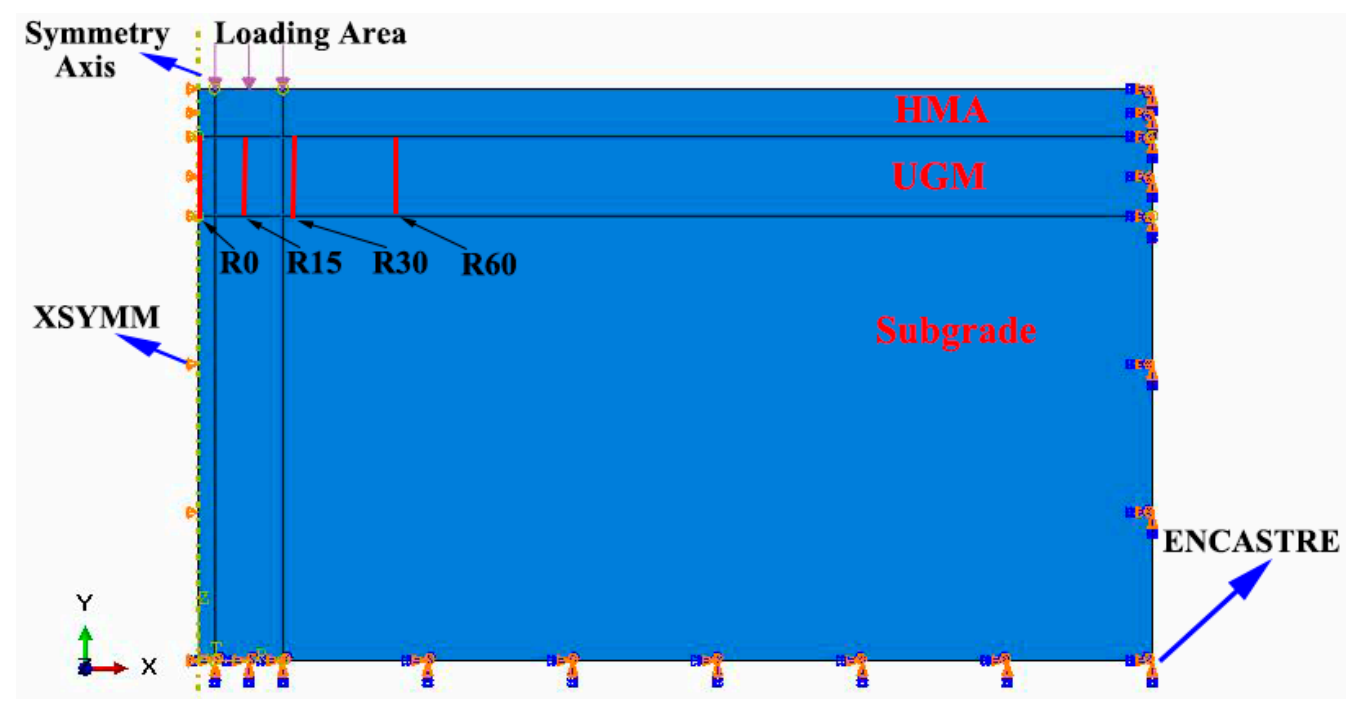

Figure 3. 2-Dimensional model of pavement structure.

With the standard axial load of $100 \mathrm{kN}$, the equivalent load pressure was $25 \times 10^{3} / 0.213=117.4 \mathrm{kPa} \cdot \mathrm{m}$ based on the static equivalence principle [31]. The total loading time was $20 \mathrm{~s}$, and each analysis step time period was $0.2 \mathrm{~s}$ with periodic amplitude in a half sinusoid wave. The current analyses didn't consider the dynamic issue caused by the vehicular load.

In the 'Step' module of the FE model, 'Static, General' was chosen as the procedure type. The element type CAX8 was adopted for the finite domains. The size of mesh was $2.5 \mathrm{~cm} \times 2.5 \mathrm{~cm}$ near the loading areas. The single mode biased seeding was used, and the seed became $2.5 \mathrm{~cm}$ to $10 \mathrm{~cm}$ along the loading area to the right boundary.

As for the model parameters of the structure layers, the linear viscoelastic model was adopted for HMA layer referenced from $[12,13]$. Poisson's ratio and transient modulus of elasticity were 0.35 and $9840 \mathrm{MPa}$, respectively. The Prony series of generalized Maxwell solid model was simulated by shear and bulk relaxation modulus, listed as Table 1 . An elastic model was adopted for soil subgrade layer, with Poisson's ratio of 0.4 and elastic modulus of $45 \mathrm{MPa}$. The parameters of the Mohr-Coulomb and Druck-Prager constitutive models were shown in Tables 2 and 3. The parameters of the revised SMP model can be found in [5].

Table 1. Prony series parameter of linear viscoelastic model.

\begin{tabular}{cccccc}
\hline $\boldsymbol{i}$ & $\mathbf{1}$ & $\mathbf{2}$ & $\mathbf{3}$ & $\mathbf{4}$ & $\mathbf{5}$ \\
\hline$G_{i} / K_{i}$ & $6.31 \times 10^{-1}$ & $2.51 \times 10^{-1}$ & $8.47 \times 10^{-2}$ & $2.67 \times 10^{-2}$ & $6.66 \times 10^{-3}$ \\
$\tau_{i}$ & $2.06 \times 10^{-2}$ & $1.73 \times 10^{-1}$ & 1.29 & 5.35 & $1.06 \times 10^{-2}$ \\
\hline
\end{tabular}


Table 2. Parameters of Mohr-Coulomb model.

\begin{tabular}{cccccc}
\hline \multirow{2}{*}{ Parameter Type } & \multicolumn{2}{c}{ Elastic Part } & \multicolumn{3}{c}{ Plastic Part } \\
\cline { 2 - 6 } & $\begin{array}{c}\text { Young's } \\
\text { Modulus (MPa) }\end{array}$ & $\begin{array}{c}\text { Possion's } \\
\text { Ratio }\end{array}$ & $\begin{array}{c}\text { Friction } \\
\text { Angle }\left({ }^{\circ}\right)\end{array}$ & $\begin{array}{c}\text { Cohesion } \\
(\mathbf{k P a})\end{array}$ & $\begin{array}{c}\text { Dilation } \\
\text { Angle }\left({ }^{\circ}\right)\end{array}$ \\
\hline Value & 400 & 0.35 & 49.06 & 19.6 & 0 \\
\hline
\end{tabular}

Table 3. Parameters of Druck-Prager model.

\begin{tabular}{cccccc}
\hline \multirow{2}{*}{ Parameter Type } & \multicolumn{2}{c}{ Elastic Part } & \multicolumn{3}{c}{ Plastic Part } \\
\cline { 2 - 6 } & $\begin{array}{c}\text { Young's } \\
\text { Modulus (MPa) }\end{array}$ & $\begin{array}{c}\text { Possion's } \\
\text { Ratio }\end{array}$ & $\begin{array}{c}\text { Friction } \\
\text { Angle }^{(}{ }^{\circ}\end{array}$ & $\begin{array}{c}\text { Flow Stress } \\
\text { Ratio }\end{array}$ & $\begin{array}{c}\text { Dilation } \\
\text { Angle ( }{ }^{\circ} \text { ) }\end{array}$ \\
\hline Value & 400 & 0.35 & 49.06 & 0.8 & 0 \\
\hline
\end{tabular}

In the pavement structure, the plastic strains of the UGM layer model were compared using the three elasto-plastic models during the first 100 loading cycles. Taking the symmetry axis as zero point, $0,0.15,0.30$ and $0.60 \mathrm{~m}$ from the symmetry axis were selected as analyses paths which denoted as R0, R15, R30 and R60, respectively, as seen in Figure 3. The analysis points started from the surface of UGM layer, which were at 0.15, 0.20, 0.25, $0.30,0.35$ and $0.40 \mathrm{~m}$ along the axial direction, respectively.

\subsection{Plastic Strain Analyses of UGM}

\subsubsection{Horizontal Normal Plastic Strain}

It is generally believed that UGMs do not produce tensile strain, but in an actual situation, UGMs produce plastic tensile or compressive strain due to the particle rotation or movement under the load effect. Therefore, nominal plastic strains were used to represent the plastic strains of the UGM layer in this study.

With the three elasto-plastic constitutive models, the UGM layer produced obvious plastic strains, including horizontal nominal tensile and compressive strain. Near the center of the loading area, the tensile strain in the middle and bottom part of UGM layer was obviously greater than that in other areas (shown in Figure 4). Comparing the nominal tensile strain from the three models, the distribution of plastic strain from the Mohr-Coulomb model was relatively concentrated. It had a sharp increase in the middle layer. This indicated that the Mohr-Coulomb model was prone to produce rapid plastic strain growth areas, which would lead to structural damage. For the Druck-Prage model, there were only tensile strains and the strain of the UGM surface layer tended to 0 . For the revised SMP model, the distribution of plastic strain was uniform with an obvious gradient. Moreover, it had a good relationship with the loading area, but it was not quite obvious for the Mohr-Coulomb and Druck-Prage models. The nominal tensile strain occurred under the loading area, resulting in the lateral movement of particles, and then a nominal compressive strain appears on both sides of the loading area. This was closely consistant with the actual situation of vehicular loading on a pavement surface [11,33,34].

However, the distribution of plastic strain from the revised SMP model was different from the predictions using the nonlinear anisotropic elastic-plastic model from the literature [6]. The plastic strains of the latter model were mainly distributed in the upper part of UGM layer. This was due to the anisotropic elasticity modulus, which had different stiffness modulus in horizontal and vertical directions [6,12-14]. The strain distribution of Druck-Prage and revised SMP models was smooth and continuous due to the fact the criteria had no angle. The stiffness modulus near the loading area was greater than that in other areas. UGM layer was the stress-dependent material, and the modulus associated with stress state. 


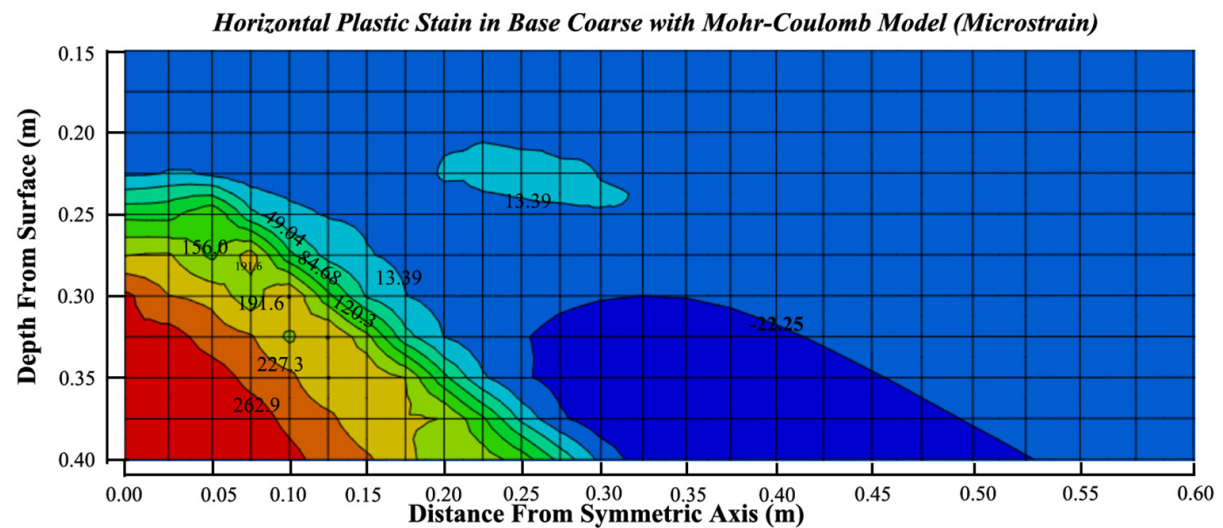

(a)

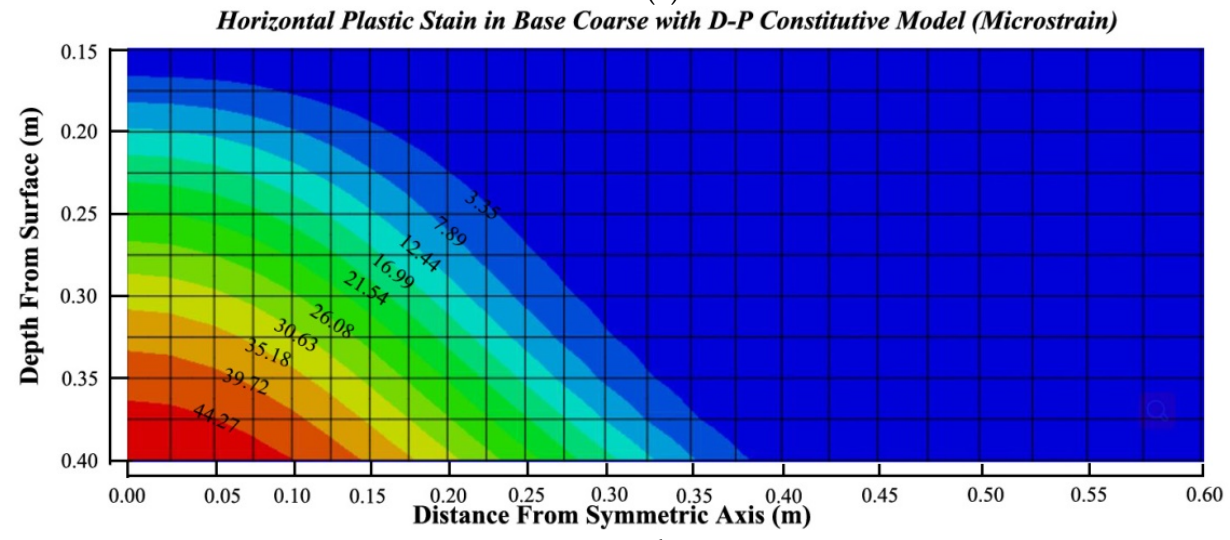

(b)
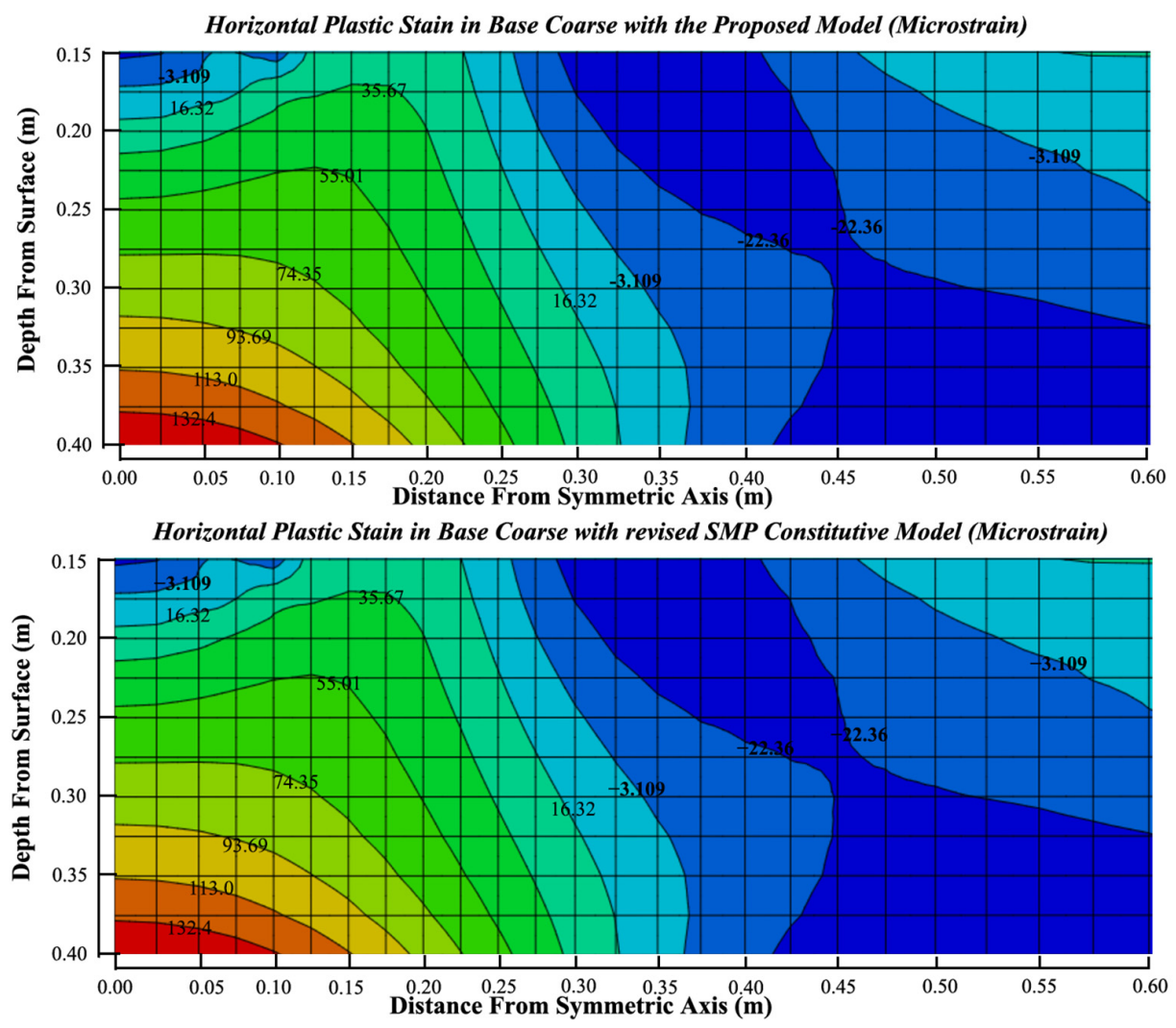

(c)

Figure 4. Distribution of horizontal nominal plastic strain of UGM layer with the three models (a) Mohr-Coulomb model, (b) Druck-Prage model, (c) revised SMP model. 
Figure 5 suggests that little horizontal plastic strain appears on the top surface of UGM layer when Mohr-Coulomb and Druck-Prage models are adopted. The greatest horizontal nominal tensile strain of the Mohr-Coulomb model was up to $298.5 \mu \varepsilon$ at the bottom layer in the center of loading area. This was about two times greater than that obtained from the revised SMP model, which indicated that Mohr-Coulomb model would produce greater plastic strains. This may cause the loosening of the UGM layer at the bottom and increase the indirect rutting. However, the maximum plastic strain of Druck-Prage model was only $45 \mu \varepsilon$, which was smaller thant that of the revised SMP model. In addition, there was a transition area between tensile strain and compressive strain for the revised SMP and MohrCoulomb models. The transition area was at around R15 to R30 for the Mohr-Coulomb model and R30 to R60 for the revised SMP model, whereas, there was no transition area for the Druck-Prage model. At different depths, the horizontal plastic strain changed greatly and irregularly for the Mohr-Coulomb model, but it varied linearly for the revised SMP and Mohr-Coulomb models.

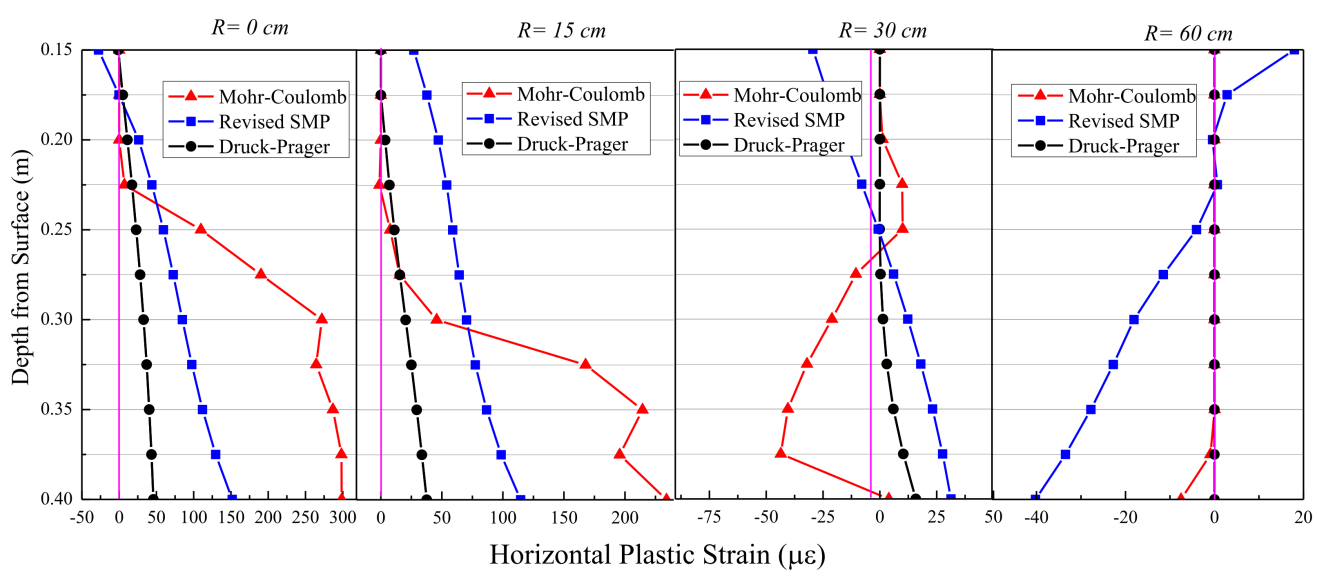

Figure 5. Horizontal plastic strain of an UGM layer using the three models.

\subsubsection{Vertical Normal Plastic Strain}

Like the horizontal plastic strain, Figure 6 shows that the vertical plastic strain of the Mohr-Coulomb model was distributed in a highly concentrated way, and that of the revised SMP and Drcuk-Prage models was relatively uniform. In addition, the curves of vertical plastic strain in the Mohr-Coulomb model were not smooth. The maximum nominal vertical compressive strain occurred at the bottom in the centerline of loading area. For the Mohr-Coulomb and Druck-Prage models, all the vertical plastic strains were compressive strains, while, there were smaller tensile strains on both sides of the loading area in the revised SMP model. These results are in line with the loading state of a pavement structure under actual conditions. Bulging appears on both sides of the loading area due to the greater shear stress, showing that the revised SMP model can describe the dilatancy effect caused by the loads [35,36].

The variation of the vertical plastic strain along the depth is shown in Figure 7 , where the strains increase gradually and the change rate of plastic strains is higher near the centerline of the loading area. When the Mohr-Coulomb and Druck-Prage models were used, there was almost no vertical plastic strain in the depth range of $0 \sim 7.5 \mathrm{~cm}$ from UGM top surface. After that, the plastic strain produced by the Mohr-Coulomb model increased sharply. The plastic compressive strain at the bottom of UGM layer reached $595 \mu \varepsilon$ in R0, and it was up to $509.8 \mu \varepsilon$ in R15. The plastic compressive strain for the revised SMP model was $303.4 \mu \varepsilon$ at R0, and $253.7 \mu \varepsilon$ at R15, respectively. The plastic strains were about half of that from Mohr-Coulomb model. However, the plastic strain of Druck-Prage model was much smaller than that of the other two models. Along with the increase of depth, the variation of plastic strain linearly increased. This was due to the Druck-Prage criterion considered the intermediate principle stress compared with the Mohr-Coulomb model. Under condition of three-direction stress, the strength and stiffness of the UGM layer was 
enhanced so that the plastic strain was much smaller. In addition, the Druck-Prage criterion had no angle resulting in a smooth distribution of the plastic strain. As for the revised SMP model, the stiffness of the revised SMP model increased gradually along with the loading cycles. In the initial state, the calculated modulus of the revised SMP model was relatively lower. However, the Druck-Prage model had a sharp increased stiffness due to the three-direction stress, and it hardly varied along with the loading cycles. Therefore, the plastic strain of Druck-Prage model was smaller than that of the revised SMP model.

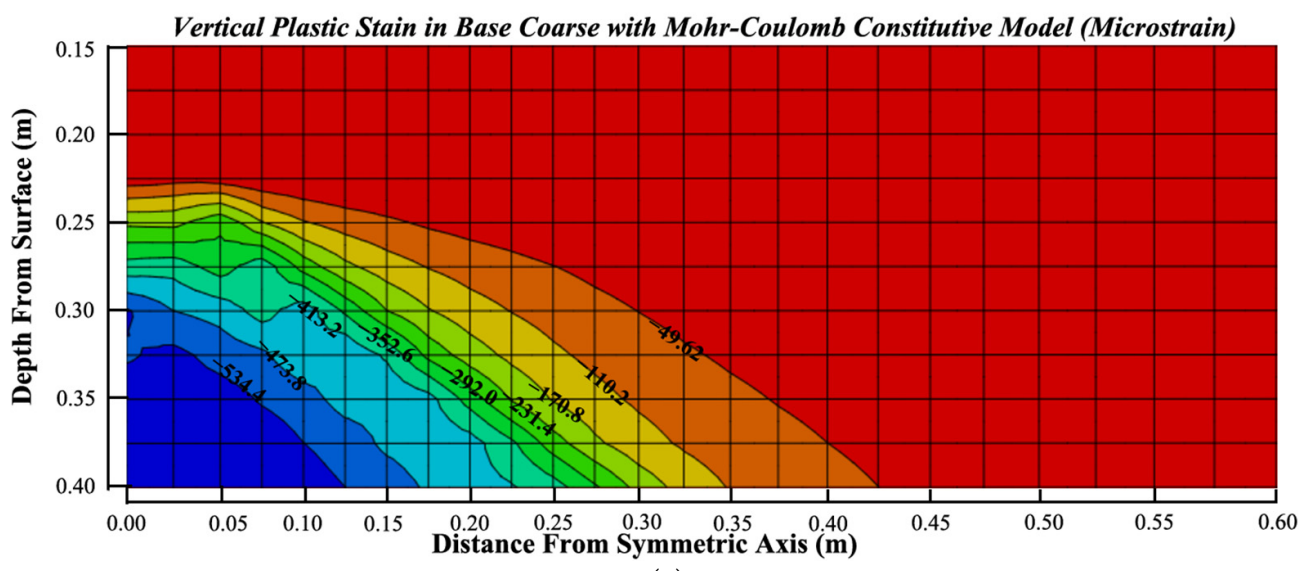

(a)

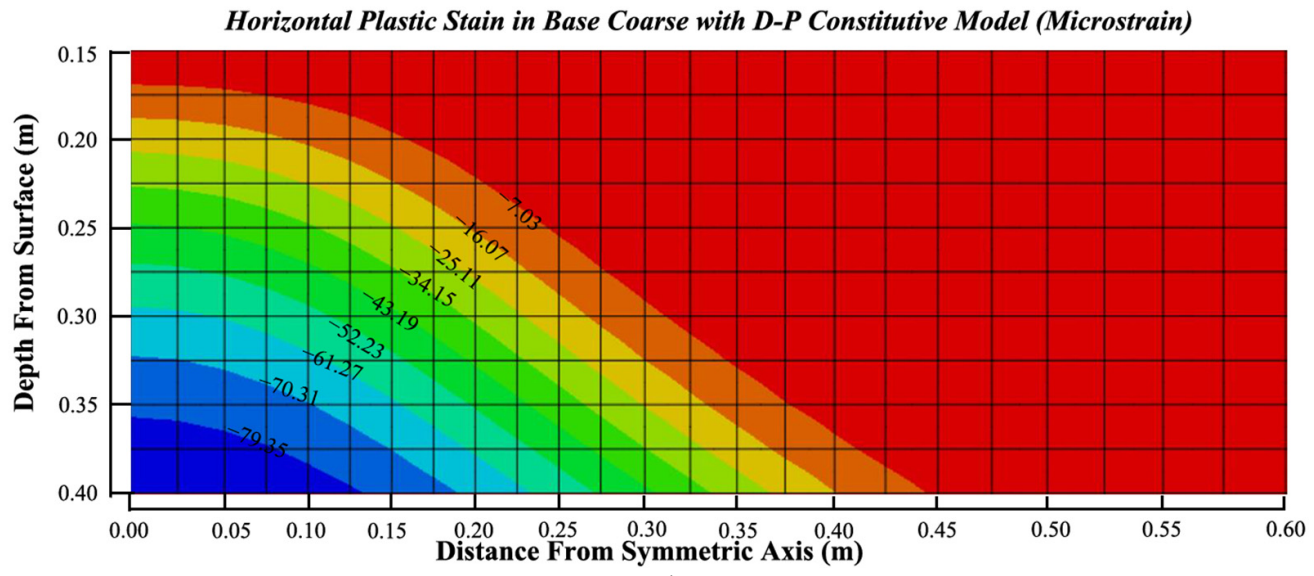

(b)

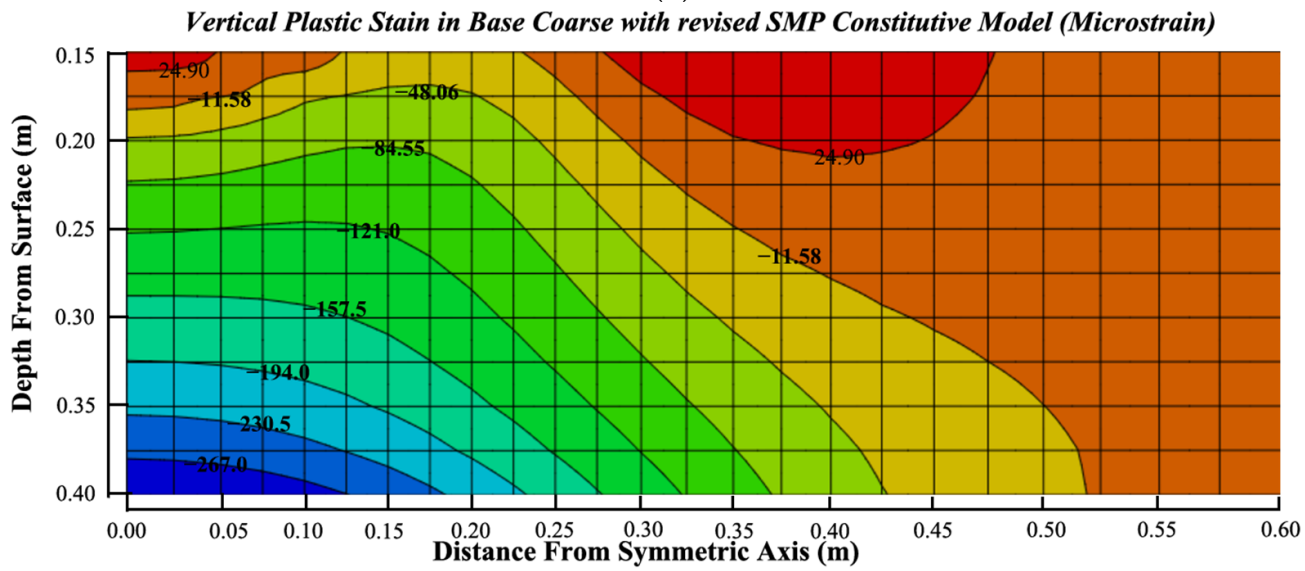

(c)

Figure 6. Distribution of vertical nominal plastic strain of UGM layer with the three models (a) Mohr-Coulomb model, (b) Druck-Prager model, (c) Revised SMP model. 


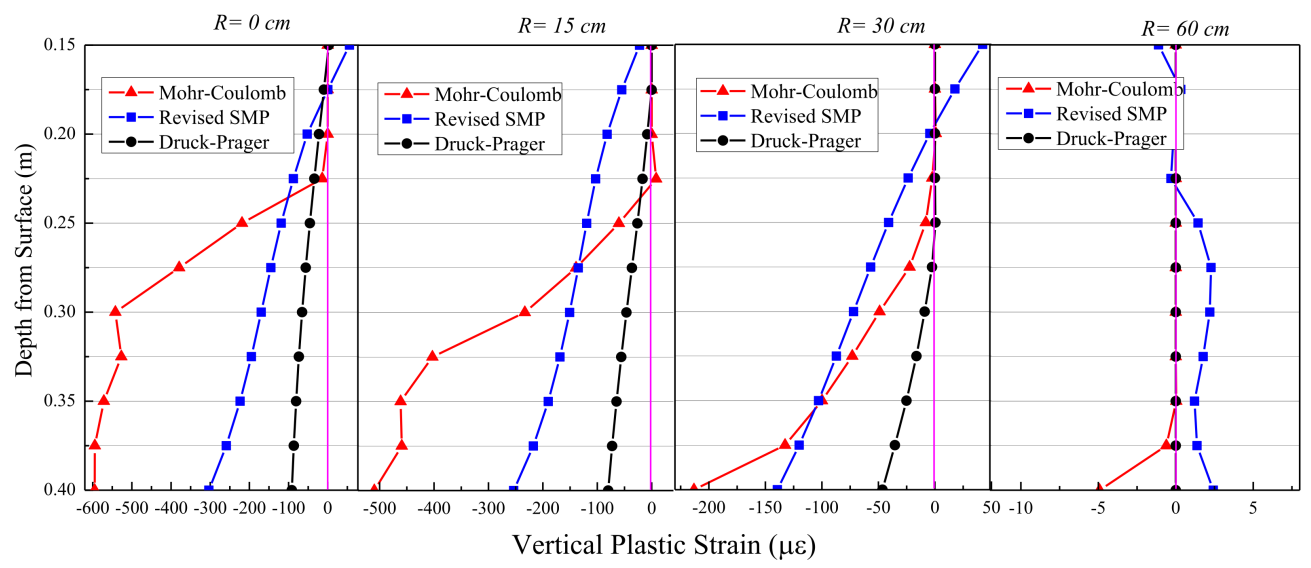

Figure 7. Vertical plastic strain of UGM layer using the three models.

Using the revised SMP model, the vertical plastic tensile strains were $55.5 \mu \varepsilon$ and $42.3 \mu \varepsilon$ at two sides of the loading area on the surface of UGM layer. This showed that the revised SMP model had the possibility of arching. It had strong relevance with the shear failure at the edge loading area under the actual load action, showing that the revised SMP model can describe the dilatancy effect caused by loads. However, there was no vertical plastic strain at the top of UGM layer using Mohr-Coulomb and Druck-Prage models, which was inconsistent with the actual conditions.

The above results show that Mohr-Coulomb model would not produce horizontal and vertical plastic strains at the top surface of UGM layer, but very high ones at the bottom of the UGM layer. Moreover, it had a sharp change at the position of 5-10 cm depth of the UGM layer. The plastic strains in the Druck-Prage model were the smallest among the three models. For the vertical plastic strain, there was only compressive strain and only tensile strain for the horizontal plastic strain. When using the revised SMP model, the horizontal and vertical plastic strains changed approximately linearly with the increase of depth. The plastic strain would appear on the top surface of UGM layer. This had a well correlation with the deformation of top surface at the actual pavement structure layer. It can be seen that the revised SMP model had advantages over the Mohr-Coulomb and Druck-Prage models in the characterizing of the plastic strain of UGM.

\subsubsection{Vertical Plastic Strain and Loading Cycle}

In the typical three-layer pavement structure, the vertical stress on the top surface of UGM layer was $65 \mathrm{kPa}$ using the three elastic-plastic model. Then at the centerline of the loading system, the average vertical plastic strain of UGM layer obtained by the three models as shown in Figure 8. When the Mohr-Coulomb and Druck-Prage models were adopted for UGM layer, the plastic strains increased rapidly in the initial loading cycles, which were up to $275 \mu \varepsilon$ and $90 \mu \varepsilon$, respectively. In the following loading cycles, the calculated plastic strain had a small growth, and it increased by $35 \mu \varepsilon$ and $12 \mu \varepsilon$, respectively. For the revised SMP model, the plastic strain was only $18 \mu \varepsilon$ at the first loading cycle. It had an obvious increase tendency during the following loading cycles, and the growth was up to $160 \mu \varepsilon$. Figure 8 suggested that the plastic strain would continuously increase after 100 loading cycles.

Comparing the plastic strains, it showed that the plastic strains calculated by the MohrCoulomb model were significantly greater than those calculated by the revised SMP model. However, the plastic strain rate of Mohr-Coulomb was far smaller than that of the revised SMP model. The plastic strain of Mohr-Coulomb model mainly occurred during the first several loading cycles. With the increase of load cycles, the yield hardening stage was short and increment of the plastic strain was small. Using the revised SMP model, the loading cycle was introduced into the yield surface and hardening law which would change with the increased loading cycles. Therefore, the plastic strain presented an obviously increasing 
tendency. Before the first 30th loading cycle, the plastic strain from the Druck-Prage model was greater than that from the revised SMP model. And it reversed after the loading cycle was above the 30th loading cycle. Similar as the Mohr-Coulomb model, the plastic strain calculated by the Druck-Prage model changed little along with the loading cycle.

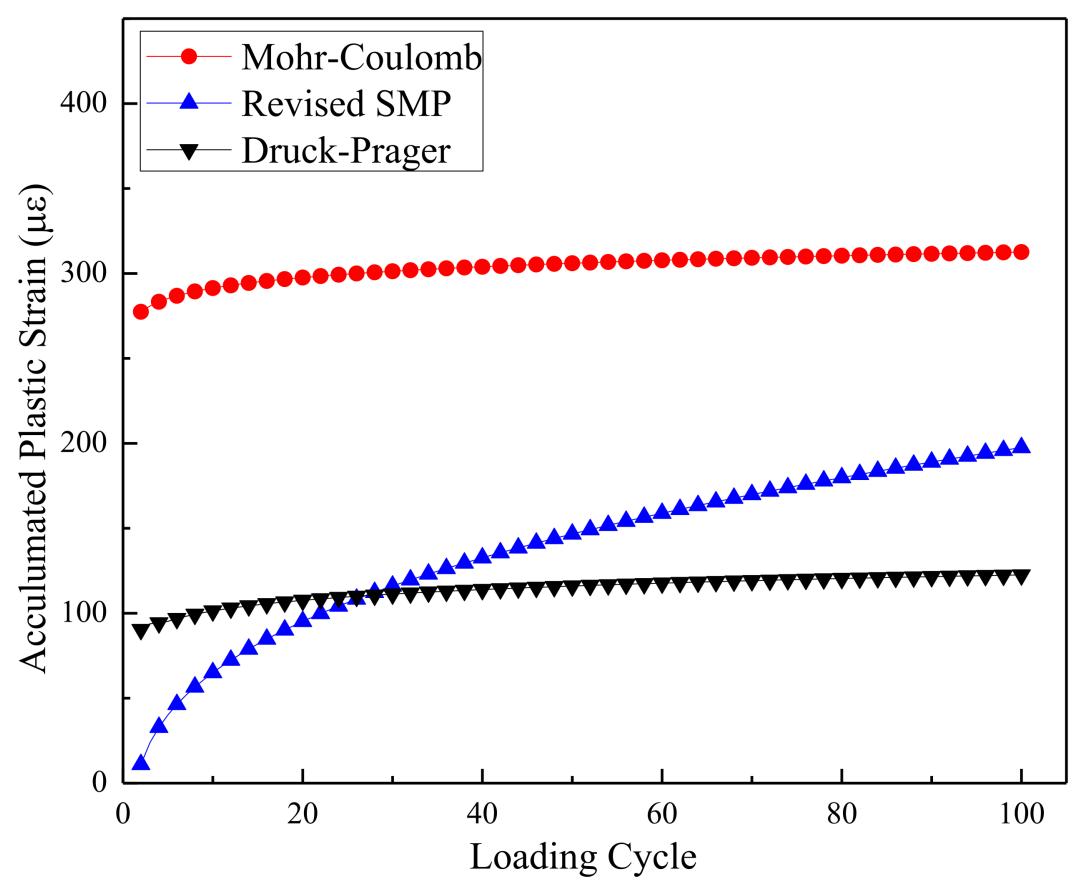

Figure 8. Relationship of average vertical plastic strain and loading cycle using the three models.

When comparing with the experimental results of UGM in the literature [11,26,33], it showed that the plastic strain calculated by the revised SMP model can well describe the deformation properties of UGM. The Mohr-Coulomb and Druck-Prage models cannot characterize the process of long-term load performance.

\subsection{Average Compressive Strain of UGM Layer and Compressive Strain of Subgrade}

Using the three models for the $F E$ numerical analyses, the average plastic compressive strain and the average elastic strain of UGM layer, the compressive strains of subgrade at top surface and the tensile strains of asphalt layer at bottom were obtained in the symmetry axis with 100 loading cycles, as shown in Table 4 .

Table 4. Strains in different structure layers using the three models.

\begin{tabular}{ccccc}
\hline Constitutive Model & $\begin{array}{c}\text { Tensile Strain at Bottom } \\
\text { of HMA Layer }(\mu \varepsilon)\end{array}$ & $\begin{array}{c}\text { Average Plastic } \\
\text { Compressive Strain of } \\
\text { UGM }(\mu \varepsilon)\end{array}$ & $\begin{array}{c}\text { Average Elastic } \\
\text { Strain of UGM }(\mu \varepsilon)\end{array}$ & $\begin{array}{c}\text { Compressive Strain on } \\
\text { Top of Subgrade }(\mu \varepsilon)\end{array}$ \\
\hline Mohr-Coulomb Model & 300.74 & 312.3 & 418.2 & 799.1 \\
Revised SMP Model & 300.67 & 222.8 & 278.4 & 780.1 \\
Druck-Prager Model & 298.5 & 50.3 & 107.5 & 773.5 \\
\hline
\end{tabular}

With the three models, the tensile strains at bottom of HMA layer and compressive strains on top of subgrade layer showed similar values, with little differences. It shows that the average elastic and plastic strain of UGM and compressive strain of subgrade were smaller than those from the Mohr-Coulomb model. In contrast, the average plastic compressive strain of UGM from the revised SMP model accounted for $71.3 \%$ of the MohrCoulomb model, and the average plastic compressive strain produced by Druck-Prage model was only $22.6 \%$ of the revised SMP one. It stated that UGM layer would produce greater vertical plastic compressive strain by the Mohr-Coulomb model and smaller plastic 
strain from the Druck-Prage model. Using the revised SMP model, the average elastic strain was 0.6 times that of the Mohr-Coulomb model and 2.6 times that of the DruckPrage model. This suggested that the modulus in the revised SMP model was greater than that in the Mohr-Coulomb model, but smaller than that in the Druck-Prage model. The resistance and hardening modulus of UGM in the revised SMP model increased gradually with loading cycles. However, the hardening modulus of the Mohr-Coulomb and Druck-Prage models almost maintained the same level. For the UGM layer, the average vertical deformation calculated by the revised SMP model of UGM was smaller than the Mohr-Coulomb model and greater than Druck-Prage model. Namely, the Mohr-Coulomb model would overestimate the deformation of UGM, and Druck-Prage model would underestimate the deformation of UGM.

The results showed that the revised SMP model can better represent the plastic strain and its development process in UGMs under repeated loads. After 100 loading cycles, the plastic deformation of the UGM layer produced by the revised SMP model was 0.557 $\mathrm{mm}$, while it was $0.78 \mathrm{~mm}$ and $0.155 \mathrm{~mm}$ using the Mohr-Coulomb and Druck-Prage models, respectively. The plastic deformation of UGM layer is an important part of rutting in granular base pavementa. When the Mohr-Coulomb model was used, the plastic strain of UGM layer may be over-predicted, leading to the overestimation of rutting in the earlier service period. On the contrary, the rutting depth may be underestimated by the Druck-Prage model.

As for the vertical compressive strain on the top surface of subgrade, the strains are similar for the three models. This was related to the stress diffusion ability of UGM layer. When the elasto-plastic model was used, the stiffness of structure layer was smaller than that of the elastic model. It has stronger stress diffusion ability using the elastic model, so that the vertical stress was relatively small on the top of the subgrade. On the other hand, the UGM layer deformed facing to the load transmitted from the upper layer. Although the used models were different, the UGM layer had different deformation responded to the same transmitted load so that the load on the top of the subgrade maintained the same level. Therefore, there was little difference for the vertical compressive strain on the top surface of subgrade using the three models.

Compared with the results in the literature $[6,12,13]$, the calculated results of plastic strain and deformation were smaller in this study. There were several reasons for this: First, the axial load was about $730 \mathrm{kPa}$ in the literatures, while the axial load was $117.4 \mathrm{kPa}$ in this study. Second, the elastic modulus of UGM in the literatures was about 90 400 MPa, while the elastic modulus in this study was $400 \mathrm{MPa}$. In addition, the anisotropy was not considered in the revised SMP mode. It was worth noting that the tensile strain at the bottom of asphalt layer was the same when different constitutive models were used for UGM. It was related to the elastic modulus, Poisson's ratio and thickness of structure layer were the same in different constitutive models.

\section{Conclusions}

With the revised SMP, Mohr-Coulomb and Druck-Prage models, the strains of UGM layer were analyzed and compared. The following summaries and conclusions were obtained from the numerical simulation:

(1) Using the three models, the maximum horizontal and vertical plastic strains of UGM are at the bottom of the loading areas centerline. At the position of $5 \sim 10 \mathrm{~cm}$ of the UGM layer, the plastic strains change sharply for the Mohr-Coulomb model but smooth for the revised SMP and Druck-Prage models. The horizontal plastic tensile and compressive strains exist in the top surface of UGM in the revised SMP model, and the tensile strain is obvious in the middle and lower part of UGM layer and the compressive strain distributes on the both sides for the loading areas. However, there are no vertical plastic tensile strains in the Mohr-Coulomb and Druck-Prage models. With the revised SMP model, vertical plastic tensile strains appear on both 
sides of the loading area. This phenomenon is closely related to the dilatancy of the material, proving the reasons for the rutting caused by the UGM layer.

(2) Compared with the Mohr-Coulomb and Druck-Prage models, the revised SMP model can better represent the accumulated process of plastic strain under repeated loads. There is an obvious increment in the first several loading cycle by the Mohr-Coulomb and Druck-Prage models, but little changes in the subsequent loading cycles. This indicates that the revised SMP model can better describe the process of the plastic strain accumulation in the actual loading condition. In addition, the rutting is over-predicted by the Mohr-Coulomb model and underestimated by the Druck-Prage model during the early loading, which may result in the ahead or delay of maintenance.

(3) With the three models, the compressive strains of subgrade on top surface and the tensile strains of asphalt layer on the bottom are similar. The Mohr-Coulomb model has the greatest average plastic and elastic strains, and the Druck-Prage model produces the smallest plastic and elastic strains during the first 100 loading cycles. This result is related to the hardening law used in the revised SMP model, which will be a long process until it reaches the elastic shakedown state.

Based on the validation of the laboratory tests, the finite element analyses were conducted using the revised SMP model in this study. The results show that this model has the advantage in describing the calculation process of plastic strain under repeated loads. There are still some shortcomings and limitations, such as stress-dependence and anisotropy, which are not included in the model. The completely continuous of contact relationship between UGM and other layers seems unsatisfactory after the use of the revised SMP model. In the next step, our plan is to apply the revised SMP model in the real pavement structure which will consider the plasticity of the HMA and subgrade layers. Moreover, the calculations will be compared with the actual monitoring data. These aspects will be the main directions for the future study.

Author Contributions: N.L.: Conceptualization, Methodology, Formal analysis, Investigation, Writing-original draft; B.M.: Conceptualization, Methodology, Resources; H.W.: Conceptualization, Writing - review \& editing. All authors have read and agreed to the published version of the manuscript.

Funding: This research received no external funding.

Acknowledgments: The supports from the Talent Technology Foundation in Xi'an University of Architecture and Technology (No RC1907) and Project funded by China Postdoctoral Science Foundation (No 2019M663649) are greatly appreciated.

Conflicts of Interest: The authors declare no conflict of interest.

\section{References}

1. Dawson, A.; Mundy, M.J.; Huhtala, M. European Research into Granular Material for Pavement Bases and Subbases. Transp. Res. Rec. J. Transp. Res. Board 2000, 1721, 91-99. [CrossRef]

2. Lekarp, F.; Isacsson, U.; Dawson, A. State of the Art. II: Permanent Strain Response of Unbound Aggregates. J. Transp. Eng. 2000, 126, 76-83. [CrossRef]

3. Habiballah, T.; Chazallon, C. An elastoplastic model based on the shakedown concept for flexible pavements un-bound granular materials. Int. J. Numer. Anal. Methods Geomech. 2005, 29, 577-596. [CrossRef]

4. Chazallon, C.; Hornych, P.; Mouhoubi, S. Elastoplastic Model for the Long-Term Behavior Modeling of Unbound Granular Materials in Flexible Pavements. Int. J. Geomech. 2006, 6, 279-289. [CrossRef]

5. Li, N.; Ma, B.; Wang, H.; Sun, W. Development of elasto-plastic constitutive model for unbound granular materials under repeated loads. Transp. Geotech. 2020, 23, 100347. [CrossRef]

6. Zhang, Y.; Gu, F.; Luo, X.; Birgisson, B.; Lytton, R.L. Modeling Stress-Dependent Anisotropic Elastoplastic Unbound Granular Base in Flexible Pavements. Transp. Res. Rec. J. Transp. Res. Board 2018, 2672, 46-56. [CrossRef]

7. Werkmeister, S.; Dawson, A.; Wellner, F. Permanent Deformation Behavior of Granular Materials and the Shakedown Concept. Transp. Res. Rec. J. Transp. Res. Board 2001, 1757, 75-81. [CrossRef]

8. Werkmeister, S.; Dawson, A.R.; Wellner, F. Permanent deformation behaviour of granular materials. Road Mater. Pavement Des. 2005, 6, 31-51. [CrossRef] 
9. Erlingsson, S.; Rahman, M.S. Evaluation of Permanent Deformation Characteristics of Unbound Granular Materials by Means of Multistage Repeated-Load Triaxial Tests. Transp. Res. Rec. J. Transp. Res. Board 2013, 2369, 11-19. [CrossRef]

10. Zhang, J.; Peng, J.; Liu, W.; Lu, W. Predicting resilient modulus of fine-grained subgrade soils considering relative compaction and matric suction. Road Mater. Pavement Des. 2021, 22, 703-715. [CrossRef]

11. Li, N.; Wang, X.; Qiao, R.; Ma, B.; Shao, Z.; Sun, W.; Wang, H. A prediction model of permanent strain of unbound gravel materials based on performance of single-size gravels under repeated loads. Constr. Build. Mater. 2020, 246, 118492. [CrossRef]

12. Wang, H.; Al-Qadi, I.L. Importance of Nonlinear Anisotropic Modeling of Granular Base for Predicting Maximum Viscoelastic Pavement Responses under Moving Vehicular Loading. J. Eng. Mech. 2013, 139, 29-38. [CrossRef]

13. Al-Qadi, I.L.; Wang, H.; Tutumluer, E. Dynamic Analysis of Thin Asphalt Pavements by Using Cross-Anisotropic StressDependent Properties for Granular Layer. Transp. Res. Rec. J. Transp. Res. Board 2010, 2154, 156-163. [CrossRef]

14. Tutumluer, E.; Thompson, M.R. Anisotropic Modeling of Granular Bases in Flexible Pavements. Transp. Res. Rec. J. Transp. Res. Board 1997, 1577, 18-26. [CrossRef]

15. Zhang, Y.; Birgisson, B.; Lytton, R.L. Weak Form Equation-Based Finite-Element Modeling of Viscoelastic Asphalt Mixtures. J. Mater. Civ. Eng. 2016, 28, 04015115. [CrossRef]

16. Chen, G. Study on the Permanent Deformation Predietion Model of Graded Crushed Stone through Simulations. Ph.D. Thesis, Chang'an University, Xi'an, China, 2009.

17. Barsanescu, P.; Sandovici, A.; Serban, A. Mohr-Coulomb criterion with circular failure envelope, extended to ma-terials with strength-differential effect. Mater. Des. 2018, 148, 49-70. [CrossRef]

18. Tu, H.; Zhou, H.; Lu, J.; Gao, Y.; Shi, L. Elastoplastic coupling analysis of high-strength concrete based on tests and the Mohr-Coulomb criterion. Constr. Build. Mater. 2020, 255, 119375. [CrossRef]

19. Darabi, M.K.; Kola, R.; Little, D.N.; Garg, N. Time-dependent Drucker-Prager-Cap model coupled with PANDA (Pavement Analysis Using Nonlinear Damage Approach) to predict rutting performance of flexible pavements. Constr. Build. Mater. 2020, 244, 118326. [CrossRef]

20. Matsuoka, H.; Nakai, T. Stress-Deformation and Strength Characteristics of Soil under Three Different Principal Stresses. Proc. Japan Soc. Civ. Eng. 1974, 232, 59-70. [CrossRef]

21. Matsuoka, H.; Hoshikawa, T.; Ueno, K. A General Failure Criterion and Stress-Strain Relation for Granular Materials to Metals. Soils Found. 1990, 30, 119-127. [CrossRef]

22. Matsuoka, H.; Nakai, T. Relationship Among Tresca, Mises, Mohr-Coulomb and Matsuoka-Nakai Failure Criteria. Soils Found. 1985, 25, 123-128. [CrossRef]

23. Tu, S. Structure and Performance of High-Performance Graded Crush-Stone Base Course on the Interaction between Granular Materials. Ph.D. Thesis, Chang'an University, Xi'an, China, 2013.

24. Xiao, Y.; Zheng, K.; Chen, L.; Mao, J. Shakedown analysis of cyclic plastic deformation characteristics of unbound granular materials under moving wheel loads. Constr. Build. Mater. 2018, 167, 457-472. [CrossRef]

25. Xiao, Y.; Zhang, Z.; Chen, L.; Zheng, K. Modeling stress path dependency of cyclic plastic strain accumulation of unbound granular materials under moving wheel loads. Mater. Des. 2018, 137, 9-21. [CrossRef]

26. Gu, F.; Zhang, Y.; Luo, X.; Sahin, H.; Lytton, R.L. Characterization and prediction of permanent deformation properties of unbound granular materials for Pavement ME Design. Constr. Build. Mater. 2017, 155, 584-592. [CrossRef]

27. Ba, M.; Tinjum, J.M.; Fall, M. Prediction of permanent deformation model parameters of unbound base course aggregates under repeated loading. Road Mater. Pavement Des. 2015, 16, 1-16. [CrossRef]

28. Lade, P.V. Elasto-plastic stress-strain theory for cohesionless soil with curved yield surfaces. Int. J. Solids Struct. 1977, 13, 1019-1035. [CrossRef]

29. Li, N.; Ma, B.; Li, R.; Si, W. Study on performance of unbound granular materials under single-stage and multi-stage loading modes based on PUMA. J. Highw. Transp. Res. Dev. 2019, 36, 62-72.

30. Li, N.; Wang, H.; Ma, B.; Li, R. Investigation of unbound granular material behavior using precision unbound material analyzer and repeated load triaxial test. Transp. Geotech. 2019, 18, 1-9. [CrossRef]

31. Liao, G. Application of ABAQUS in Highway Engineering; Southeast University Press: Nanjing, China, 2014.

32. Zhang, Q.; Zhang, J.; Li, Z.; Wen, Z.; Yang, Y. Fatigue-Damage Model of a Pothole-Repairing Composite Structure for Asphalt Pavement. J. Mater. Civ. Eng. 2017, 29, 04017215. [CrossRef]

33. Chow, L.C. Permanent Deformation Behavior of Unbound Granular Materials and Rutting Model Development. Ph.D. Thesis, University of Illinois at Urbana-Champaign, Urbana, IL, USA, 2014.

34. Tutumluer, E.; Little, D.N.; Kim, S.-H. Validated Model for Predicting Field Performance of Aggregate Base Courses. Transp. Res. Rec. J. Transp. Res. Board 2003, 1837, 41-49. [CrossRef]

35. Qamhia, I.; Tutumluer, E.; Chow, L.C.; Mishra, D. A Framework to Utilize Shear Strength Properties for Evaluating Rutting Potentials of Unbound Aggregate Materials. Procedia Eng. 2016, 143, 911-920. [CrossRef]

36. Ma, G.; Li, H.; Yang, B.; Zhang, H.; Li, W. Investigation on the deformation behavior of open-graded unbound granular materials for permeable pavement. Constr. Build. Mater. 2020, 260, 119800. [CrossRef] 